anticonvulsant as they were imminently dying. Where prognosis was estimated, $80 \%$ of patients commencing a midazolam CSCI were felt likely to survive less than a week Seizures were controlled in $69 \%$ of patients with initial doses prescribed. 'As required' anticonvulsant medication was prescribed for 23 patients (88\%); all were prescribed subcutaneous midazolam (2.5 mg-10 mg). Phenobarbital (8 patients), buccal midazolam (one patient) and rectal diazepam (one patient) were also prescribed. The majority of patients (92\%) died and almost half (46\%) died within a week of parenteral anticonvulsant prescription.

Conclusion Levetiracetam via CSCI was the most commonly used parenteral anticonvulsant. Midazolam via CSCI tended to be used for patients with a poorer prognosis (under one week). Regional guidelines need to be reviewed to reflect clinical practice. Given the widespread use of levetiracetam, further research is warranted to guide use in the palliative care setting.

\section{SYRINGE DRIVER (CSCI) SITE REACTIONS IN SPECIALIST PALLIATIVE CARE IPU}

Amy Ritchie, Pauline Wilkinson, Chris Black. Marie Curie Hospice Belfast

10.1136/bmjspcare-2018-ASPabstracts.203

Background Syringe drivers are routinely used in palliative medicine for the subcutaneous infusion of drugs. Local site reactions can lead to patient discomfort and the potential for sub-optimal symptom control. A site reaction is defined as 'an adverse incident occurring at the point of drug delivery'. Anecdotally, we observed frequent site reactions in our clinical practice without formal record of prevalence within our inpatient unit. We decided to perform an audit to determine whether our practice is in keeping with local/national guidance and whether outcomes were within acceptable limits.

Methods Aims/objectives -

- Site reactions are within 'acceptable limits'

- Site reactions are recognised

- Recommendations/guidelines regarding site management are followed

- Appropriate drugs/diluents used.

Standards

- Prevalence of site reactions $<20 \%$,

- Sites inspected 4 hourly (100\%),

- Sites rotated every 7 days $(100 \%)$

- Reactions recorded (100\%)

- Diluents appropriate (100\%).

- Line changed with prescription change (100\%)

Results 46 prescriptions and sites reviewed (completed 13/12/ 2017). Site reactions observed in $8.6 \%$. $100 \%$ of sites recorded as inspected every 4 hours but zero reactions identified/recorded. Rotation frequency documented $-72 \%$-average 10 days, and not documented $-28 \%$. Diluent appropriate $100 \%$. Line changed with a change in prescription $-39 \%$.

Conclusion We have demonstrated compliance with standards $1,2 \& 5$. However, problems were identified with standards 2, 3, $4 \& 6$. 100\% of reactions identified were documented as inspected 4 hourly highlighting poor recognition of reactions. Average length of site rotation exceeded 7 days. And only $38 \%$ of lines were changed with prescription change. Our recommendations include reviewing processes of site inspection. To provide education on site reaction recognition and the importance of line change in conjunction with prescription change. And to standardise clear documentation of site rotation and local policy adherence. Following implementation of these interventions we recommend annual re-audit to ensure standards met.

\section{CHANGING THE GOAL POSTS: EXPLORING THE EXPERIENCES OF COMMUNITY PALLIATIVE CARE NURSES IN THE MANAGEMENT OF DELIRIUM}

Holly McGuigan, Ruth Isherwood. Strathcarron Hospice

\subsection{6/bmjspcare-2018-ASPabstracts.204}

Background Delirium is a syndrome of decreased cognitive function, consciousness and attention. It has an acute onset and fluctuating course. The prevalence of delirium amongst palliative care in-patients is about $30 \%$. There is no similar data for out-patients. A focus group was conducted at a Scottish hospice to explore the experiences of clinical nurse specialists (CNSs) in managing delirium in the community. This formed part of a wider quality improvement project on hospice patients with delirium.

Method Two facilitators explored the experiences of CNSs in the management of delirium. Discussions were recorded and transcribed to allow analysis of themes.

Results The focus group involved eight CNSs and generated 21 pages of text. Data was reviewed by two members of the project team. Themes emerged including importance of skilled assessment, impact on families, challenges in the management of delirium at home and the impact of delirium on choices available at the end of life.

The CNSs reflected on the impact of delirium on patients' families, who experienced guilt, fear and a sense of early bereavement. They also recognised particular challenges associated with managing patients with delirium in the community. They felt pressure to avoid admission to hospital but also felt there was a lack of the support services required to offer a non-pharmacological approach to management at home. Drugs were resorted to earlier than would be necessary in a different care setting to manage symptoms and risk. The CNSs also spoke of 'walking away' but being left with feelings of responsibility for the situation. Delirium was also felt to negatively impact on choices at the end of life e.g. place of death.

Conclusion Management of delirium in the community represents unique challenges compared with an in-patient setting. There is a need for educational resources targeting professionals working in the community.

\section{Transition | Posters $178-179$}

\section{FACTORS ASSOCIATED WITH AN EFFECTIVE TRANSITION FROM CHILDREN'S TO ADULT SERVICES BY YOUNG ADULTS WITH LIFE-LIMITING CONDITIONS IN IRELAND}

Helen Kerr, Peter O'Halloran, Honor Nicholl, Jayne Price. Queen's University Belfast, Trinity College Dublin, Kingston University London

10.1136/bmjspcare-2018-ASPabstracts.205 